Article

\title{
On the Design of Virtual Reality Learning Environments in Engineering
}

\author{
Diego Vergara ${ }^{1, *}$, Manuel Pablo Rubio ${ }^{2}$ and Miguel Lorenzo ${ }^{3}$ \\ 1 Technological Department, University Catholic of Ávila, C/Canteros, s/n, 05005 Avila, Spain \\ 2 Construction Department, University of Salamanca, Campus Viriato, 37008 Zamora, Spain; mprc@usal.es \\ 3 Department of Mechanical Engineering, University of Salamanca, ETSII, Avda. Fernando Ballesteros, 2, \\ 37700 Béjar (Salamanca), Spain; mlorenzo@usal.es \\ * Correspondence: diego.vergara@ucavila.es or dvergara@usal.es; Tel.: +34-920-251-020
}

Academic Editors: Carolina Cruz-Neira, Marcos Fernández Marín and Cristina Portalés Ricart Received: 15 April 2017; Accepted: 24 May 2017; Published: 1 June 2017

\begin{abstract}
Currently, the use of virtual reality (VR) is being widely applied in different fields, especially in computer science, engineering, and medicine. Concretely, the engineering applications based on VR cover approximately one half of the total number of VR resources (considering the research works published up to last year, 2016). In this paper, the capabilities of different computational software for designing VR applications in engineering education are discussed. As a result, a general flowchart is proposed as a guide for designing VR resources in any application. It is worth highlighting that, rather than this study being based on the applications used in the engineering field, the obtained results can be easily extrapolated to other knowledge areas without any loss of generality. This way, this paper can serve as a guide for creating a VR application.
\end{abstract}

Keywords: virtual reality; design; virtual laboratory; engineering; education; instruction

\section{Introduction}

From the first development of virtual reality (VR) in the sixties [1], the use of virtual reality (VR) has spread over a wide variety of fields. A simple indicator of this growing use of VR is the number of research papers including the term VR as the focus of researching. This way, from the simple consultation of a bibliographic database (SCOPUS), a clear growing trend is revealed (Figure 1), especially in three different areas: (i) computer science; (ii) engineering; and (iii) medicine. Among these areas, the highest number of VR applications published in scientific journals corresponds to the engineering field. Thus, according to Figure 1, a total number of 10651 papers in the SCOPUS database includes "virtual reality" in the title, and 3854 of them also include "engineering", which consists of more than a third (around 36\%) of the total published papers. Furthermore, the analysis of the 4371 papers containing "virtual reality" and "computer science" in the title reveals that 1190 papers of those deal with engineering-related topics as well. Thus, approximately one half $(47 \%)$ of the published research papers related to VR are linked to the engineering field. These percentages are taken from the data included in the SCOPUS database up to 2016 (Figure 1).

Within the engineering field, nowadays VR is being effectively used in engineering education [2-5] since the use of VR presents several advantages, namely: (i) VR allows simulating in real time the use of otherwise unavailable expensive laboratory equipment [6-9]; (ii) the use of VR avoids potential damages to a real machine caused by students' misuse during practical classes [9]; (iii) VR solves the difficulty of developing practical classes in a real laboratory environment when the groups are overcrowded [10]; (iv) VR improves the prevention of occupational hazards [11-15]; and (v) VR allows the students to interact with complete manufacturing processes, which would be practically impossible otherwise [16-18]. 


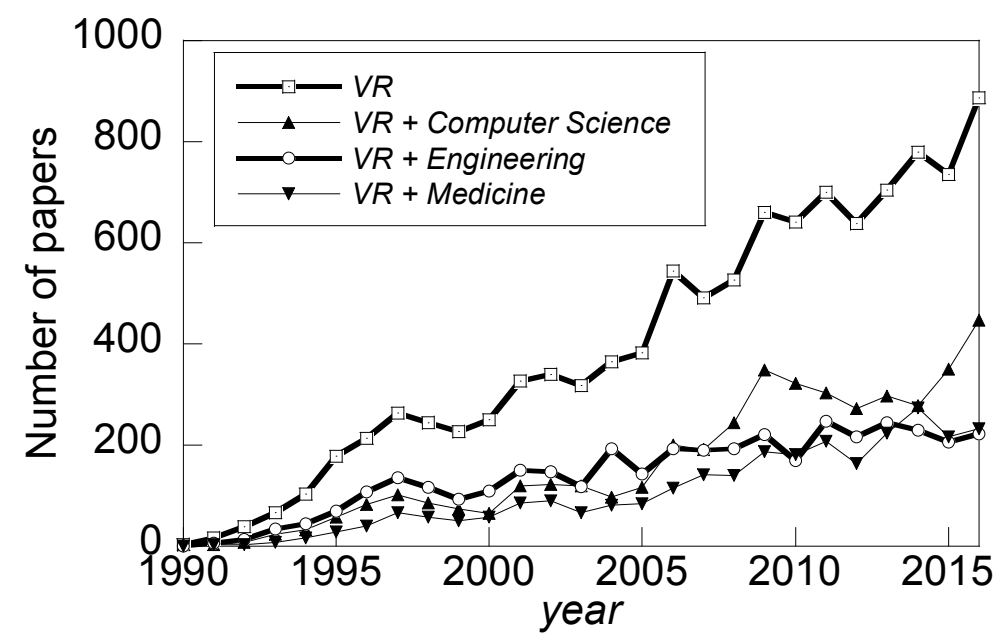

Figure 1. The number of research papers indexed in SCOPUS related with the following keywords in the title: (i) Virtual Reality; (ii) Virtual Reality and Computer Science; (iii) Virtual Reality and Engineering; and (iv) Virtual Reality and Medicine. (Data collected on February 2017).

This paper deals with didactic virtual resources designed by means of VR systems. Concretely, a general flowchart for designing applications of VR in engineering is shown in this paper. Furthermore, the different developing environments that could be used for designing such applications are analyzed, comparing their advantages and disadvantages.

\section{Background of VR Applications}

Three-dimensional VR resources cover a wide variety of applications from those relatively simple (e.g., didactic virtual laboratories $[2,12,19]$ ) to the highly complex (e.g., immersive virtual reality training for military (VIRTSIM, www.motionrealityincorporated.com). In general terms, VR applications in education can be classified according to visualization and interaction devices [3] into two wide categories: (i) non-immersive (the well-known window in the world), where the user's vision to the world is by means of the flat screen of a computer acting as a "window" (Figure 2); and (ii) immersive, which completely introduces the user into a virtual world by using glasses with two small screens placed in front of the user's eyes (Figure 2). Each one of the previous categories are also divided into the following subcategories. On one hand, the non-immersive resources are classified according to the device type used for interacting with the virtual world: (i) by using conventional computer peripheral devices, e.g., mouse, keyboard, etc. [9,10,12,15,20-22]; and (ii) by using specially designed interaction devices similar to the ones used in the real control, e.g., machine operation consoles or vehicle control cockpits [23]. On the other hand, VR immersive applications are also subdivided into two subcategories, according to the visualization system of the virtual world: (i) the head-mounted display (HMD), which consists of active glasses with a small screen placed properly in front of each eye (Figure 2b) [7,24-27]; and (ii) the virtual CAVE (cave automatic virtual environment), where the virtual world is projected on the walls, ceiling, and floor of a room by diverse stereoscopic projectors (Figure 2). In this last case, the user must wear passive stereo glasses [28,29] to achieve a 3D view of the virtual world. The main disadvantage of the virtual caves is the high cost, which makes the use of this type of immersive VR limited. On the other hand, the use of an HMD can often cause some level of cyber sickness. 


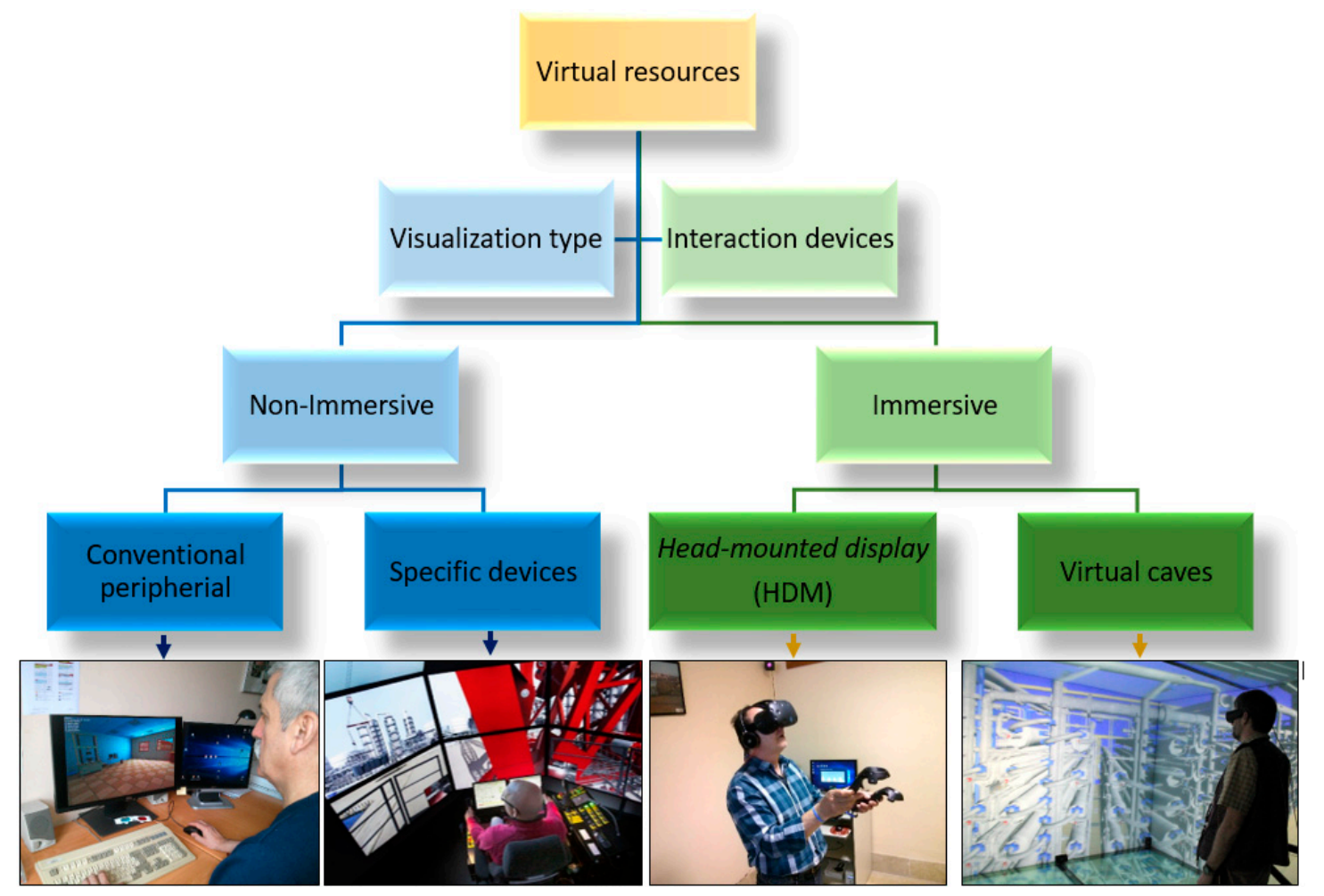

Figure 2. Classification of VR resources according to visualization and interaction devices. Specific device images are from the construction company Mammoet (www.mammoet.com). Virtual cave image is from the Technical University of Zvolen, Slovakia (http:/ / etools.tuzvo.sk/cave).

In the field of engineering education, the most common resources recently designed are based on 3D Virtual Laboratories (3D-VLs) [9,10,12,15,20,30-33], since these tools solve several difficulties frequently associated with practical classes in engineering laboratories: (i) the danger of using products or machines; (ii) overcrowded classes; and (iii) timetable schedule availability of the laboratory. Thus, 3D-VLs allow each student to carry out their own practice and obtain an experience very close to the real one. Furthermore, many 3D-VLs provide technical results similar to those obtained in a real practice and allow for including questions or exercises in order to evaluate the teaching-learning process.

Nevertheless, the use of VR in engineering education spreads further than the use of 3D-VLs. On one hand, VR applications focus on the design and simulation of an engineering project, which are based not only on the use of techniques but also on the interactive verification of the obtained results $[21,25,26]$. On the other hand, other VR applications aim to improve the comprehension of different concepts: the spatial comprehension of abstract concepts, complex three-dimensional graphics, production processes, manufacturing, operation processes, assembly, etc. [22,34-38]. Finally, VR learning environments have also been related to serious games since approximately 20 years ago and, in this way, such environments enhance student motivation through a gamification procedure of the teaching-learning process [39]. Furthermore, kinaesthetic learning and all the embodied elements in learning are supported by VR [40].

\section{Design of VR Applications}

Before beginning with the design and development of a VR application, some key questions should be considered: (i) the use of such a VR resource must improve the teaching-learning process (it must enhance motivating activities that yields to a more effective learning); and (ii) the effort required to develop such a tool must be worth the costs (in essence, it depends on the computational advances of the moment). If the answer to either of the previous questions is no, then the VR resource 
should not be developed in such a case. For this reason, there are not specific applications for all knowledge areas and, therefore, the usefulness of VR has not yet been fully explored in many fields. This paper is focused on the current main application of VR devices in engineering; the 3D simulation of environments and processes.

On the basis of Pantelidis' suggestions about using VR [41], the first step for designing a VR application is to define and to select the specific objectives to be fulfilled by the device. Subsequently, among all desired aims, only those that could be carried out by means of a computer-generated simulation are selected. Then, the following step is to determine which of the desired aims could use a 3D interactive simulation. This way, if none of the aims are addressed, the VR will not be useful.

Once the feasibility of applying VR to the chosen topic is checked, the process of creating the VR application is constituted by the following steps (Figure 3):

- To decide the most adequate realism level for achieving each objective, varying on a scale from very symbolic or schematic to very realistic.

- To choose the level of user interaction with the VR environment, which determines (i) the senses involved (e.g., tactile, sonic, or visual only), and (ii) the degree of control and immersion that the user will have.

- To select the hardware and software programming that best fit the objectives proposed, according to the options adopted in the previous steps.

- Then, the virtual world is modelled, interactivity is programmed, and the VR application is generated. It must be considered that reducing the response time is essential (as in any computer application) for obtaining a VR experience as real as possible and for minimizing cyber sickness.

- Finally, the VR device is tested by a group of pilot users. The result of the test allows for verification if the desired objectives are reached, and for making the necessary modifications otherwise.

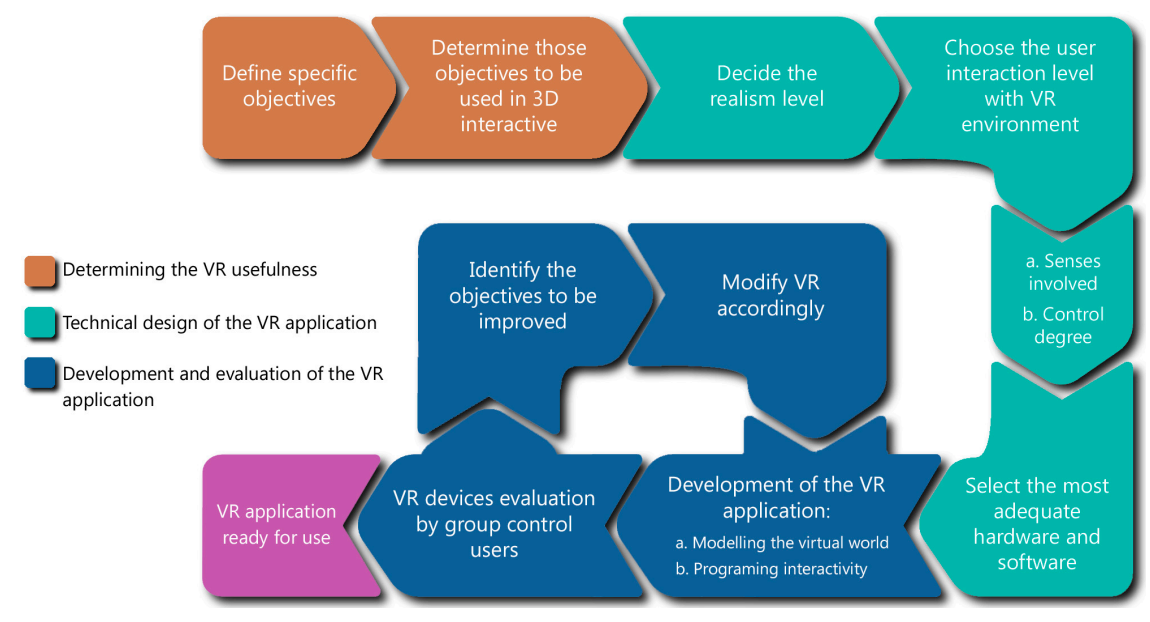

Figure 3. General flowchart for designing a VR application.

After discussing the general procedure for developing a VR application (Figure 4), the most important technical aspects in the development process are detailed as follows: level of user interaction and control; hardware devices; software for VR programming. 


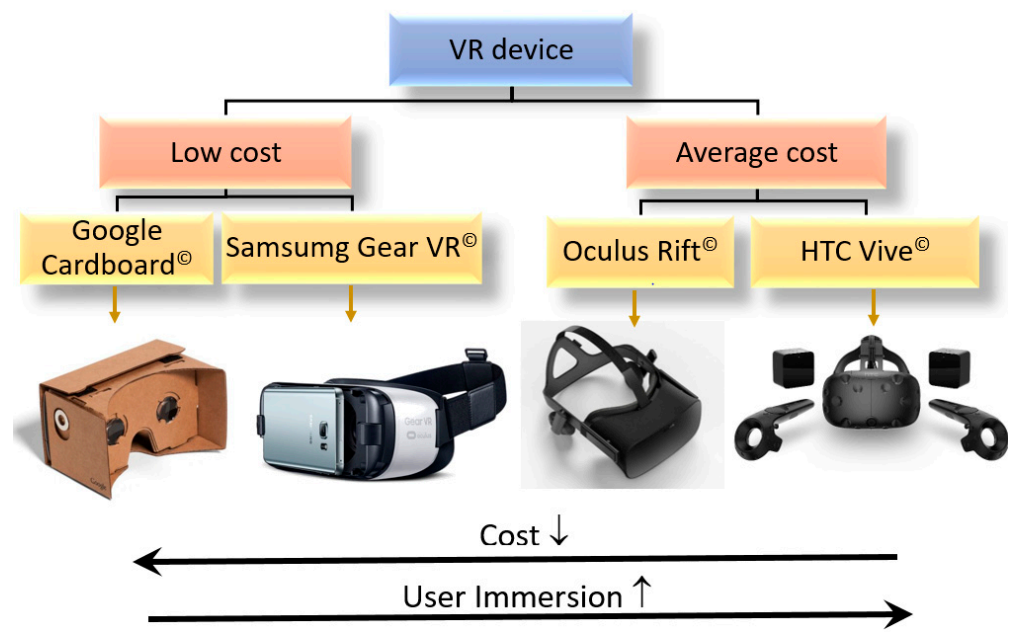

Figure 4. Commercial VR devices: (i) low cost: Google Cardboard@ (vr.google.com) and Samsung Gear VR@ (www.samsung.com/global/galaxy/gear-vr); (ii) average cost: Oculus Rift@ (www.oculus. com/rift) and HTC Vive@ (www.vive.com).

\subsection{Level of User Interaction and Control}

The interaction and the difficulty of designing of a VR application can be classified into three basic levels [42]: (i) passive; (ii) exploratory; and (iii) interactive.

- Passive Level: The user interaction with the VR environment is low. Such an environment is similar to a movie but in a 3D immersive environment. The user has no control over what happens. However, the user has the freedom to decide where to look and the interaction can involve several senses such as sight, hearing, and even touch (feeling what is happening around him). The most common example of passive VR is $360^{\circ}$ video [43].

- Exploratory Level: In this interaction type, the VR environment allows the user both (i) to move around the virtual world and (ii) to choose where to look. Although this level implies a great improvement in functionality and immersion, interaction and control over the environment are scarce. Users can see and change their position in the virtual world but they cannot touch. By way of example, architectural walks or the simplest virtual museums may be quoted [44].

- Interactive Level: The user interaction with the VR environment is high. Such an environment allows users to explore, to control and even to modify the virtual environment. The level of interactivity can widely vary depending on (i) intended objectives; (ii) the number of senses acting; (iii) the available hardware devices; and (iv) the used programming software. Most of the current VR applications are included in this level.

\subsection{Hardware Devices}

The hardware selection depends mainly on the chosen level of VR application properties, such as realism, immersion, and interaction (according to the objectives initially intended for the VR application). The higher the number of involved user senses, the higher the complexity of the devices and their corresponding programming. The most common senses involved in a current VR application are sight and hearing. User's hands are only used in handling the controls, since tactile stimulation (touch, temperature, etc.) is still poorly developed.

In non-immersive systems, the vision device is the computer monitor, and the hardware component controlling the representation of the virtual world on the computer screen is the computer graphics card. For a fluid interaction, a high-performance graphics card is required (high number of graphics processors, installed shared memory, and high speed data bus). A conventional graphic card included in a computer for playing videogames is enough. 
However, in immersive systems, a special device is used: the head-mounted display (HMD), with one small screen in front of each eye. This type of VR device was initially developed in the eighties but, at that period, the possibilities of both resolution and speed were not enough for making the user experience completely immersive. This way, the first glasses providing the required services were commercialized in 2015. Nowadays, several models of VR devices are available in the market with a high variety of cost and user immersion degree. Thus, two categories of the current commercial devices (not considering research laboratories) can be distinguished: (i) low cost and low immersion level, e.g., Google Cardboard (Google, Mountain View, CA, United States) and Samsung Gear VR (Samsung Group, Seoul, South Korea); and (ii) average cost and acceptable immersion level, e.g., Oculus Rift (Oculus VR, Menlo Park, California, United States) and HTC Vive (HTC, Xindian District, New Taipei City, China). In Figure 4, a scheme is shown to categorize these commercial VR devices.

Table 1 includes the main features of each one of the VR devices analyzed in this paper. Each one of them is briefly discussed as follows:

- Google Cardboard@ (Figure 4): The easiest and cheapest way to experiment with VR, having a smart phone with a gyroscope. Google designed such glasses in cardboard, and this simple design became as a reference for models made using other materials. The computer system is a smartphone where the user can run applications and videogames or play VR videos. Such a VR device includes two $40 \mathrm{~mm}$ focal length lenses and two magnets that interact with the phone magnetometers. The advantages of this system are: (i) low cost; (ii) large amount of content, especially $360^{\circ}$ videos; and (iii) versatility, since it works with most smartphone models, whereas the disadvantages can be summarized by: (i) the low quality of the VR experience and (ii) the fact that it is uncomfortable to use.

- Samsung Gear VR@ (Figure 4): A VR device with a much more rigid structure, a more attractive appearance, and a more comfortable use than the Google Cardboard@ $\odot$. Several additional elements are included in these VR glasses: better optics, better field of view $\left(96^{\circ}\right.$ Samsung Gear VR๑ vs. $90^{\circ}$ Google Cardboard $\odot$, see Table 1), and better head tracking due to a series of sensors placed specifically to achieve this end. Although its price constantly grows, it is still affordable. The main disadvantages are: (i) the low versatility, since these VR glasses only work with certain models of Samsung smartphones, and (ii) a relatively low level of immersion.

- Oculus Rift $\odot$ (Figure 4): The origin of a real revolution of VR technology. Oculus Rift $\odot$ was a project initiated by Kickstarter, the world's largest funding platform for creative projects, and was later acquired by Facebook. The more significant hardware components included in this VR device are: (i) VR goggles; (ii) 360-degree surround headphones; and (iii) a sensor that records the movements of the user's body. Oculus Rift $\odot$ requires a high-end computer with a very high performance graphics card. Oculus Rift@ does not have external sensors and only includes an infrared sensor inside the glasses, consequently, it is not capable of detecting movements within the virtual zone as HTC Vive@ $\odot$ does. Therefore, the main disadvantage is the limited user movements allowed in space due to the restriction imposed by the cable linking the headset to the computer.

- HTC Vive@ (Figures 2 and 4): The high-end VR headset developed by the maker of HTC@ mobile phones and the videogame corporation Valve@ $\odot$. In this VR device, a high level of immersion is achieved due to the use of (i) VR stick controls (used with the hands) that allow users to interact with objects within the VR environment, and (ii) sensors placed on the walls of the room that build a virtual space where the user can freely move. As in the case of Oculus Rift $\odot$, a high-end computer is necessary for using HTC Vive@). 
Table 1. Main features of the current commercial VR glasses.

\begin{tabular}{|c|c|c|c|c|}
\hline & $\begin{array}{c}\text { Google } \\
\text { Cardboard@ }\end{array}$ & $\begin{array}{l}\text { Samsung } \\
\text { Gear VR@ }\end{array}$ & Oculus Rift@ & HTC Vive@ \\
\hline Screen & Depends on & S. AMOLED & OLED & OLED \\
\hline Type/Resolution & Smartphone & $2.560 \times 1.440$ pixels & $2.160 \times 1.200$ pixels & $2.160 \times 1.200$ pixels \\
\hline $\begin{array}{c}\text { Refresh } \\
\text { Frequency }(\mathrm{Hz})\end{array}$ & $\begin{array}{l}\text { Depends on } \\
\text { Smartphone }\end{array}$ & 60 & 90 & 90 \\
\hline Platform Web & Google Play & Oculus Share & Oculus Home & SteamVR \\
\hline Field of View $\left(^{\circ}\right)$ & 90 & 96 & 110 & 110 \\
\hline Integrated Audio & No & No & Yes & Yes \\
\hline $\begin{array}{l}\text { Integrated } \\
\text { Microphone }\end{array}$ & No & No & Yes & Yes \\
\hline Controls & No & Touchpad & $\begin{array}{l}\text { Xbox One } \\
\text { Controller }\end{array}$ & $\begin{array}{l}\text { Two wireless } \\
\text { controllers }\end{array}$ \\
\hline Sensors & $\begin{array}{c}\text { Accelerometer, } \\
\text { gyroscope, } \\
\text { proximity sensor }\end{array}$ & $\begin{array}{c}\text { Accelerometer, } \\
\text { gyroscope, } \\
\text { proximity sensor }\end{array}$ & $\begin{array}{l}\text { Accelerometer, } \\
\text { gyroscope, } \\
\text { magnetometer, } \\
360^{\circ} \text { positional } \\
\text { tracking }\end{array}$ & $\begin{array}{l}\text { Accelerometer, } \\
\text { gyroscope, laser } \\
\text { position sensor, } \\
\text { front camera, } \\
\text { base stations }\end{array}$ \\
\hline Connections & No & MicroUSB & $\begin{array}{c}\text { HDMI, } \\
\text { USB 2.0, USB } 3.0\end{array}$ & $\begin{array}{c}\text { HDMI, } \\
\text { USB 2.0, USB } 3.0\end{array}$ \\
\hline $\begin{array}{c}\text { Minimum } \\
\text { Requirements }\end{array}$ & $\begin{array}{c}\text { A smartphone } \\
\text { based on Android } \\
\text { or iOS }\end{array}$ & $\begin{array}{l}\text { Galaxy Note 5, S6, } \\
\text { S6 edge, S6 edge+, } \\
\text { S7, S7 edge. }\end{array}$ & $\begin{array}{l}\text { NVIDIA GTX } \\
\text { 970/ AMD Radeon } \\
\text { R9 290. Intel } \\
\text { i5-4590, 8 GB RAM, } \\
\text { HDMI } 1.3\end{array}$ & $\begin{array}{c}\text { NVIDIA GTX } \\
\text { 970/AMD Radeon } \\
\text { R9 290. Intel } \\
\text { i5-4590, } \\
\text { 4 GB RAM, } \\
\text { HDMI } 1.3\end{array}$ \\
\hline Price $(€)$ & 5 & 99 & 699 & 899 \\
\hline
\end{tabular}

\subsection{Software for VR Programming}

Regardless of the hardware system, programming a VR application requires certain common tasks depending on the desired level of both realism and interactivity: (i) creating 3D environments and (ii) programming of interaction. In the early stages of VR research and development (1980s), applications were programmed directly by using high-level languages that required extensive knowledge and a lot of effort. At the time, there was no specialization of tasks, i.e., the same software was used for programming both the 3D environment and the interactivity of such an environment. Besides, since the graphic capacities of languages and equipment were very limited at that time, poor results were obtained regarding the visual aspect of the VR environment (the more important feature for achieving an adequate user immersion). In the following years, VR devices with better graphical results were developed. Besides, the work process was simplified, although a great specialization in programming was still required. In 1994, a new language emerged to represent 3D virtual reality: VRML (virtual reality modeling language), which is still used in some cases.

In recent years, advances in multimedia have encouraged the development of a new VR software that is much more powerful, providing better photorealistic graphic results and improving the ease of use, i.e., it is intended for a less expert user. Furthermore, 3D modelling tasks have been separated from interactivity programming. Thus, the diverse software currently used in VR development can be classified into two main categories: (i) 3D modelling and animation software and (ii) development engines. Within the first category (3D modelling and animation software), the three-dimensional objects are generated by using the techniques of CAD software, as well as the visual aspect of surfaces, the illumination of the surroundings, effects of nature (fire, fog, liquids, etc.), dynamic effects (forces, 
gravity, etc.), and all kinds of animation. This type of software is also used in the production of films, videogames, and projects. The most widely used 3D modelling software are:

- Blender@ (Blender Foundation, Amsterdam, Netherlands): The most popular free and open-source 3D animation and modelling software that currently exists. This software is difficult to learn.

- $\quad$ Autodesk 3DStudio Max® (Autodesk, San Rafael, CA, United States): The most used in technical applications of engineering and architecture and in the creation of videogames. This software is more affordable to learn.

- $\quad$ Autodesk Maya $\odot$ (Autodesk, San Rafael, CA, United States): The most advisable in the production of films. The main shortcoming is the high complexity in learning.

Regarding the second category, several names are used to describe it, including development engines, videogame engines (they were originally created for programming videogames), and graphic engines (they generate the interactive images used in videogames or VR applications). In the software industry, the word 'engine' refers to a program, or a part of it, that executes a certain type of task: a database engine, a transcription engine, or a graphic engine. Development engines offer the programmer a set of basic programmed functions that are common in all VR applications: (i) a rendering engine to generate 2D and 3D graphics; (ii) a collision-detecting engine; (iii) possible interactions with the environment; (iv) sounds and music; (v) animation; (vi) artificial intelligence; (vii) communication with the network; (viii) memory management, etc. Besides, development engines are easy to use and support the development for different platforms. The most used graphic engines are:

- Unity3Do (Unity Technologies, San Francisco, CA, United States): The most popular 3D videogame development engine currently available in the market. It is a flexible graphic engine offering a wide range of resources. The main advantage is its versatility. By being cross-platform, any project can be exported to both mobile (Android, IOS) and desktop operating systems (Windows, Linux and Mac OS), as well as to videogame consoles. In addition, it is also compatible with VR platforms, and it is really useful for designing projects either in 2D and 3D. Furthermore, Unity3D is easy to learn and to use, and offers a free version with some limitations.

- Unreal Engine@ (Epic Games, Cary, NC, United States): A total cross-platform engine which has been free since 2015. Unreal Engine $\odot$ is optimized for currently available consoles (including Nintendo Switch $\odot$ (Nintendo Co., Kyoto, Japan)). In addition, it supports mobile and all types of VR devices. Nowadays, Unreal@ is the reference development engine for multiple videogame and serious game applications as it is more graphically advanced than Unity3D@.

\section{Discussion and Conclusions}

The use of VR in engineering education is very promising and useful in student learning. By way of example, several didactic applications designed by the authors with VR software are shown in this section (Figures 5 and 6). In Figure 5, such resources are linked with both destructive testing materials (Figure $5 \mathrm{a}, \mathrm{b}$ ) and non-destructive testing materials (Figure 5c,d), whereas Figure 6 shows several VR applications related to engineering processes instruction (construction, hydraulic, automobile industry, etc.). The main aim of all of them is instruction in different engineering fields. 


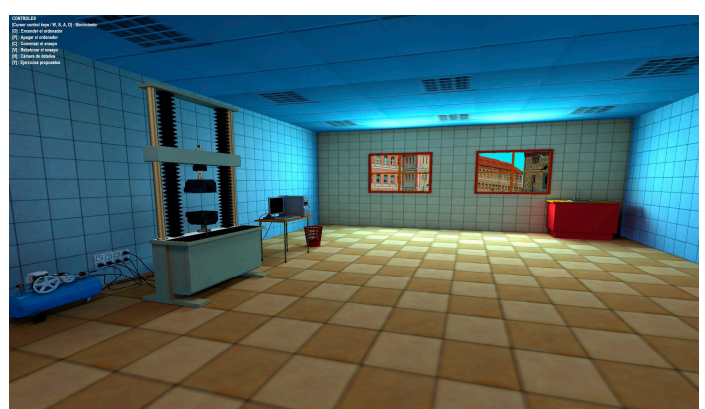

(a)

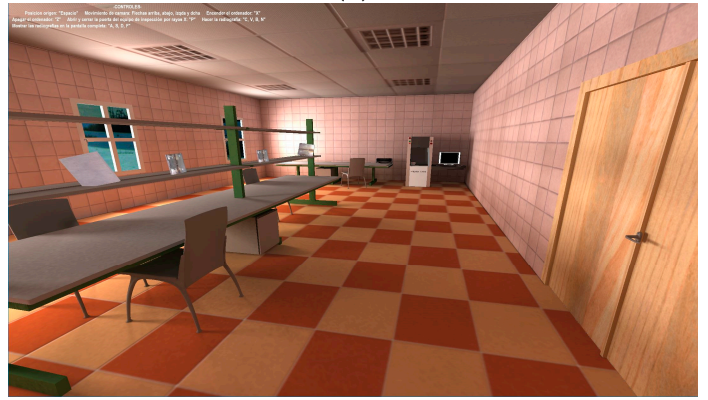

(c)

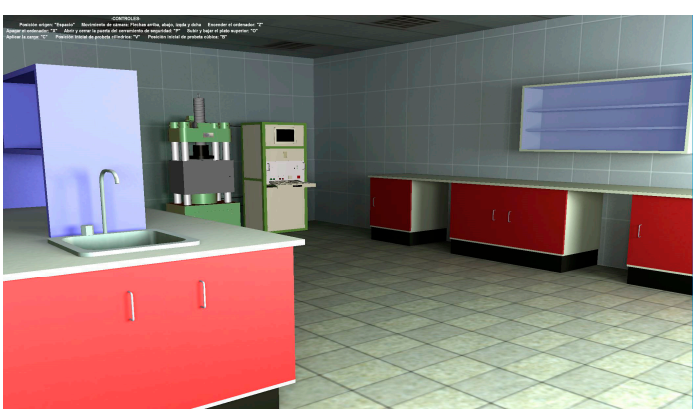

(b)

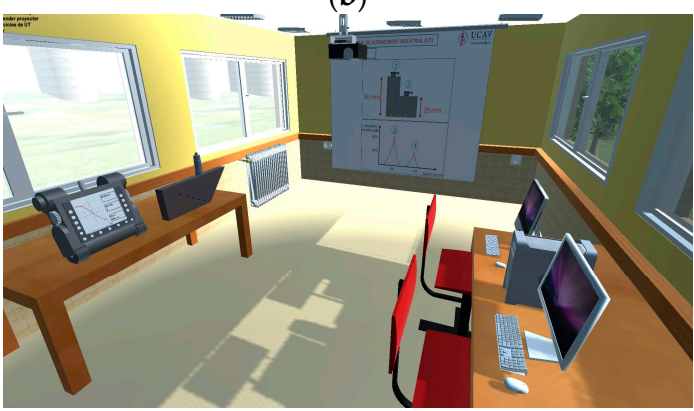

(d)

Figure 5. VR applications related to testing materials: (a) tensile testing [9]; (b) compression testing [10,12]; (c) X-ray testing [15]; (d) ultrasonic testing.

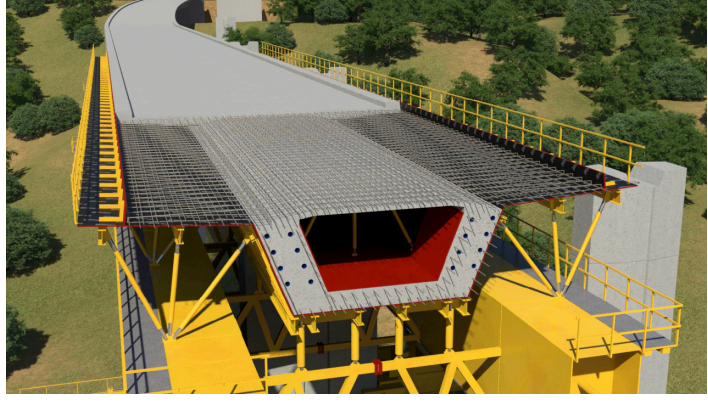

(a)

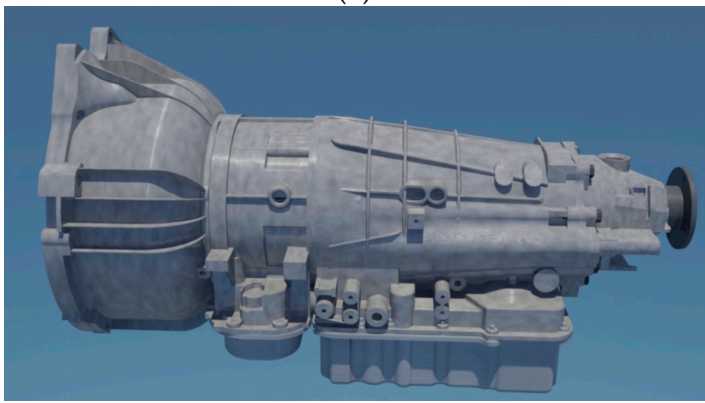

(c)

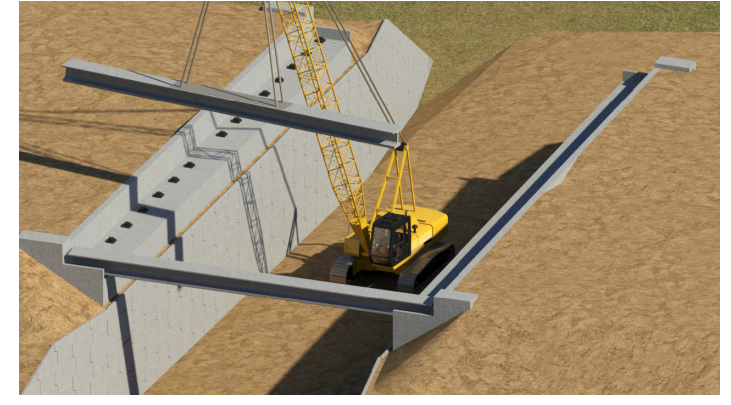

(b)

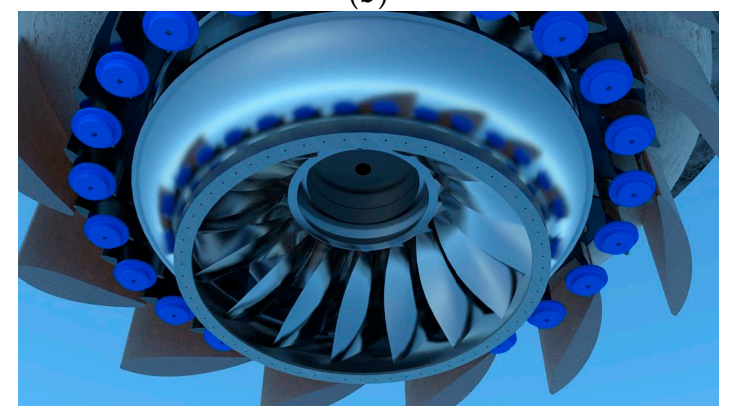

(d)

Figure 6. VR applications related to engineering: (a) bridge construction; (b) crane; (c) gearbox; (d) turbine.

On one hand, the 3D-VLs focused on destructive materials testing (tensile and compression test) shown in Figure 5a,b help engineering students to achieve active learning by putting into practice the mechanical characterization process of diverse materials through (i) a VR learning environment and (ii) a virtual exercises collection. On the other hand, the 3D-VLs dealing with non-destructive materials testing illustrated in Figure $5 c, d$ are useful for learning in a similar way how to identify the 
different types of welding defects by using either X-ray or ultrasonic testing techniques, respectively. Furthermore, the VR environments shown in Figure 6 are designed with the main objective to allow students to easily visualize the phases of the construction process of civil structures (Figure 6a,b), or the components assembly or the manufacturing process of complex multibody mechanical devices widely used in mechanical engineering such as a gearbox or a turbine (Figure $6 c, d$ ).

To reveal the usefulness of VR resources in engineering studies, diverse surveys were carried out during the last seven academic courses to recover the opinion of students enrolled in diverse engineering degrees at different universities. On the basis of the analysis of the database of 200 surveys, students considered that the most important features in VR applications [3,5] are interactivity, realism (including immersion), motivation, ease of use, and educational usefulness. From these results, several conclusions can be drawn:

- Interactivity and realism are the most important features for motivating students to use a didactic VR application. Taking into account that students are used to handling videogames designed with the latest VR technologies, outdated didactic VR applications do not awake the interest of students. Consequently, a constant effort to update VR application is necessary.

- The students highly rated the realism of the VR applications developed by the authors. Even so, students demand the use of VR resources as much as possible in order to improve their learning experience, according to survey results. Thus, collaboration between experts in a specific subject and VR technicians is necessary for designing a useful and attractive VR environment for students.

- In general terms, all the students consider these didactic VR resources easy to use (as it would be expected, considering the students' familiarity with the latest generation of videogames, which are designed with the same type of VR software).

- VR is not by itself educationally useful and, consequently, an ad hoc methodological approach must be developed using the VR as a didactic tool.

- According to students' opinion, the most important aspects in a didactic VR tool to reach a good level of educational usefulness are: (i) a collection of interactive exercises or problems and (ii) the interactivity, which must be designed for didactic purposes and, hence, the allowed movements should enhance the expected learning.

Author Contributions: D.V. and M.P.R. conceived and designed the VR applications; M.P.R. performed the VR applications; D.V., M.P.R. and M.L. analyzed and discussed the data; D.V., M.P.R. and M.L. wrote the paper.

Conflicts of Interest: The authors declare no conflict of interest.

\section{References}

1. Sutherland, I.E. The ultimate display. In Information Processing 1965, Proceedings of the IFIP Congress, London, UK, 1965; Macmillan and Co.: London, UK, 1965; pp. 506-508.

2. Dobrzański, L.A.; Honysz, R. On the implementation of virtual machines in computer aided education. J. Mater. Educ. 2009, 31, 131-140.

3. Vergara, D.; Lorenzo, M.; Rubio, M.P. Virtual environments in materials science and engineering: the students' opinion. In Handbook of Research on Recent Developments in Materials Science and Corrosion Engineering Education, 1st ed.; Lim, H., Ed.; IGI Global: Hershey, PA, USA, 2015; Chapter 8; pp. 148-165. [CrossRef]

4. Richert, A.; Shehadeh, M.; Willicks, F.; Jeschke, S. Digital Transformation of Engineering Education. Int. J. Eng. Pedagog. 2016, 6, 23-29. [CrossRef]

5. Vergara, D.; Lorenzo, M.; Rubio, M.P. On the use of virtual environments in engineering education. Int. J. Qual. Assur. Eng. Technol. Educ. 2016, 50, 30-41. [CrossRef]

6. Achuthan, K.; Murali, S. A comparative study of educational laboratories from cost \& learning effectiveness perspective. In Software Engineering in Intelligent Systems; Silhavy, R., Senkerik, R., Kominlova, Z., Prokopova, Z., Silhavy, P., Eds.; Springer: Cham, Switzerland, 2015; Volume 349, pp. 143-153. [CrossRef]

7. Hilfert, T.; König, M. Low-cost virtual reality environment for engineering and construction. Visual Eng. 2016, 4, 1-18. [CrossRef] 
8. García, J.; Entrialgo, J. Using computer virtualization and software tools to implement a low cost laboratory for the teaching of storage area networks. Comput. Appl. Eng. Educ. 2015, 23, 715-723. [CrossRef]

9. Vergara, D.; Rubio, M.P.; Prieto, F.; Lorenzo, M. Enhancing the teaching/learning of materials mechanical characterization by using virtual reality. J. Mater. Educ. 2016, 38, 63-74.

10. Vergara, D.; Rubio, M.P.; Lorenzo, M. New approach for the teaching of concrete compression tests in large groups of engineering students. J. Prof. Issues Eng. Educ. Pract. 2016. [CrossRef]

11. Dobrzański, L.A.; Jagiełło, A.; Honysz, R. Virtual tensile test machine as an example of material science virtual laboratory post. J. Achiev. Mater. Manuf. Eng. 2008, 27, 207-210.

12. Vergara, D.; Rubio, M.P.; Lorenzo, M. Interactive virtual platform for simulating a concrete compression test. Key Eng. Mater. 2014, 572, 582-585. [CrossRef]

13. Tuan, Q.; Pedro, A.; Rok, Ch.; Taek, H.; Sik, Ch.; Ki, H. A framework for using mobile based virtual reality and augmented reality for experiential construction safety education. Int. J. Eng. Educ. 2015, 31, 713-725.

14. Zhao, D.; Lucas, J. Virtual reality simulation for construction safety promotion. Int. J. Inj. Control Saf. Promot. 2015, 22, 57-67. [CrossRef] [PubMed]

15. Vergara, D.; Rubio, M.P. The application of didactic virtual tools in the instruction of industrial radiography. J. Mater. Educ. 2015, 37, 17-26.

16. Berg, L.P.; Vance, J.M. Industry use of virtual reality in product design and manufacturing: A survey. Virtual Real. 2016, 1-17. [CrossRef]

17. Batista, C.; Seshadri, V.; Rabelo, R.A.; Reinhardt, P.; Moreira, P. Applying virtual reality model to green ironmaking industry and education: A case study of charcoal mini-blast furnace plant. Miner. Process. Ind. Metall. 2017, 1-8. [CrossRef]

18. Choi, S.; Jung, K.; Noh, S.D. Virtual reality applications in manufacturing industries: Past research, present findings, and future directions. Concurr. Eng. Res. Appl. 2015, 23, 40-63. [CrossRef]

19. Vergara, D.; Rubio, M.P. Active methodologies through interdisciplinary teaching links: Industrial radiography and technical drawing. J. Mater. Educ. 2012, 34, 175-186.

20. Hashemipour, M.; Manesh, H.F.; Bal, M. A modular virtual reality system for engineering laboratory education. Comput. Appl. Eng. Educ. 2011, 19, 305-314. [CrossRef]

21. Sampaio, A.Z. Virtual reality technology applied in teaching and research in civil engineering education. J. Inf. Technol. Appl. Educ. 2012, 1, 152-163.

22. Arnay, R.; Hernández-Aceituno, J.; González, E.; Acosta, L. Teaching kinematics with interactive schematics and 3D models. Comput. Appl. Eng. Educ. 2017. [CrossRef]

23. Ki, J.-S. Interactive training simulator for aerial working platform in a virtual environment. Comput. Appl. Eng. Educ. 2011, 19, 733-738. [CrossRef]

24. Fang, X.D.; Luo, S.; Lee, N.J.; Jin, F. Virtual machining lab for knowledge learning and skills training. Comput. Appl. Eng. Educ. 1988, 6, 89-97. [CrossRef]

25. Crespo, R.; García, R.; Quiroz, S. Virtual reality application for simulation and off-line programming of the Mitsubishi move master RV-M1 robot integrated with the oculus rift to improve students training. Proc. Comput. Sci. 2015, 75, 107-112. [CrossRef]

26. Górski, F.; Buń, P.; Wichniarek, R.; Zawadzki, P.; Hamrol, A. Immersive city bus configuration system for marketing and sales education. Proc. Comput. Sci. 2015, 75, 137-146. [CrossRef]

27. Dickey, J.P.; Eger, T.R.; Frayne, R.J.; Delgado, G.P.; Ji, X. Research using virtual reality: Mobile machinery safety in the 21st century. Minerals 2013, 3, 145-164. [CrossRef]

28. DeFanti, T.A.; Dawe, G.; Sandin, D.J.; Schulze, J.P.; Otto, P.; Girado, J.; Kuester, F.; Smarr, L.; Rao, R. The StarCAVE, a third-generation CAVE and virtual reality OptlPortal. Future Gener. Comput. Syst. $2009,25$. [CrossRef]

29. Kuchera-Morin, J.E.; Wright, M.; Wakefield, G.; Roberts, Ch.; Adderton, D.; Sajadi, B.; Höllerer, T.; Majumder, A. Immersive full-surround multi-user system design. Comput. Graph. 2014, 40. [CrossRef]

30. Dobrzański, L.A.; Honysz, R. The idea of material science virtual laboratory. J. Achiev. Mater. Manuf. Eng. 2010, 42, 196-203.

31. Gao, Z.; Liu, S.; Ji, M.; Liang, L. Virtual hydraulic experiments in courseware: 2D virtual circuits and 3D virtual equipments. Comput. Appl. Eng. Educ. 2011, 19, 315-326. [CrossRef]

32. Heradio, R.; de la Torre, L.; Galán, D.; Cabrerizo, F.J.; Herrera-Viedma, E.; Dormido, S. Virtual and remote labs in education: A bibliometric analysis. Comput. Educ. 2016, 98, 14-38. [CrossRef] 
33. Xiang, S.; Wang, L.Ch. VGLS: A virtual geophysical laboratory system based on C\# and Viustools and its application for geophysical education. Comput. Appl. Eng. Educ. 2017. [CrossRef]

34. Chou, Ch.; Hsu, H.-L.; Yao, Y.-S. Construction of a virtual reality learning environment for teaching structural analysis. Comput. Appl. Eng. Educ. 1997, 5, 223-230. [CrossRef]

35. De Sousa, M.P.A.; Filho, M.R.; Nunes, M.V.A.; Lopes, A.d.C. A 3D learning tool for a hydroelectric unit. Comput. Appl. Eng. Educ. 2012, 20, 269-279. [CrossRef]

36. Vergara, D.; Rubio, M.P.; Lorenzo, M. A virtual environment for enhancing the understanding of ternary phase diagrams. J. Mater. Educ. 2015, 37, 93-102.

37. Flanders, M.; Kavanagh, R.C. Build-a-robot: Using virtual reality to visualize the Denavit-Hartenberg parameters. Comput. Appl. Eng. Educ. 2015, 23, 846-853. [CrossRef]

38. Vergara, D.; Rubio, M.P.; Lorenzo, M. Multidisciplinary methodology for improving students' spatial abilities in technical drawing. Sci. J. Educ. Technol. 2015, 5, 1-8.

39. Villagrasa, S.; Fonseca, D.; Durán, J. Teaching case: Applying gamification techniques and virtual reality for learning building engineering 3D arts. In Proceedings of the Second International Conference on Technological Ecosystems for Enhancing Multiculturality, Salamanca, Spain, 1-3 October 2014; ACM: New York, NY, USA; pp. 171-177. [CrossRef]

40. Rodríguez, N.A.; González, E.; Salinas, P.; Rios, H. Kinesthetic learning applied to mathematics using Kinect. Proc. Comput. Sci. 2013, 25, 131-135.

41. Pantelidis, V.S. Virtual reality and engineering education. Comput. Appl. Eng. Educ. 1997, 5, 3-12. [CrossRef]

42. Aukstakalnis, S.; Blatner, D. Silicon Mirage; the Art and Science of Virtual Reality; ACM, Digital Library, Peachpit Press: Berkeley, CA, USA, 1992.

43. Borisov, N.; Smolin, A.; Stolyarov, D.; Shcherbakov, P.; Trushin, V. The opportunities of applying the $360^{\circ}$ video technology to the presentation of cultural events. In Interactivity, Game Creation, Design, Learning, and Innovation; Brooks, A., Brooks, E., Eds.; Lecture Notes of the Institute for Computer Sciences, Social Informatics and Telecommunications Engineering; Springer: Cham, Switzerland, 2017; Volume 196, pp. 256-263. [CrossRef]

44. Kabassi, K. Evaluating websites of museums: State of the art. J. Cult. Herit. 2017, 24, 184-196. [CrossRef]

(C) 2017 by the authors. Licensee MDPI, Basel, Switzerland. This article is an open access article distributed under the terms and conditions of the Creative Commons Attribution (CC BY) license (http:/ / creativecommons.org/licenses/by/4.0/). 